\title{
Swimming with the fishes: validating drift diving to identify farmed Atlantic salmon escapees in the wild
}

\author{
S. Mahlum ${ }^{1,2, *}$, H. Skoglund ${ }^{1}$, T. Wiers ${ }^{1}$, E. S. Norman ${ }^{1}$, B. T. Barlaup ${ }^{1}$, \\ V. Wennevik ${ }^{3}$, K. A. Glover ${ }^{2,3}$, K. Urdal ${ }^{4}$, G. Bakke ${ }^{3}$, K. W. Vollset ${ }^{1}$ \\ ${ }^{1}$ NORCE Norwegian Research Centre, LFI, Nygårdsgt. 112, 5008 Bergen, Norway \\ ${ }^{2}$ Department of Biology, University of Bergen, Thormøhlensgate 53 A \& B, 5006 Bergen, Norway \\ ${ }^{3}$ Institute of Marine Research, PO Box 1870, Nordnes, 5817 Bergen, Norway \\ ${ }^{4}$ Rådgivende Biologer AS, Edvard Griegs vei 3, 5059 Bergen, Norway
}

\begin{abstract}
Escaped farmed Atlantic salmon Salmo salar interbreeding with wild conspecifics represents a threat to the genetic integrity and viability of wild populations. Therefore, it is necessary to accurately quantify escapees in riverine systems to monitor and mitigate interactions with wild conspecifics. Drift diving surveys are presently used in Norway to quantify the number of wild and escaped farmed salmon in rivers. However, limited information is available on the validity of the method for distinguishing escapees from wild conspecifics. Comparing the proportion of escapees calculated from drift diving (mean $=8.5 \%$ ) and net captures (mean $=8.6 \%$ ), we found that drift diving was well correlated with net captures (adj. $\mathrm{r}^{2}=0.79$ ). Furthermore, scale analysis from an independent data set demonstrated a $98 \%$ true positive rate when identifying and capturing farmed escapees during drift diving. The results of this study indicate that drift diving is an accurate and robust method for quantifying escaped farmed salmon, at least in rivers where observation conditions are adequate for snorkeling. In general, drift diving can be a valuable tool for stakeholders to quickly assess broad spatial extents with limited time and resources.
\end{abstract}

KEY WORDS: Snorkeling · Domesticated salmon - Aquaculture · Bayesian · Method comparison · Escaped farmed salmon $\cdot$ Mitigation

\section{INTRODUCTION}

The introduction of exotic species is a well-known risk to the ecological integrity of many ecosystems (Wilcove et al. 1998). Less known is the impact of introduction of non-native genotypes into a population from conspecifics through restocking programs, which has resulted in reductions in overall population fitness (Champagnon et al. 2012). The expansion of aquaculture over the last century has resulted in the unintentional introduction of domesticated animals to regions that they would not have otherwise inhabited (Naylor et al. 2001). Aquaculture facilities have provided source populations that can inadvertently escape into the surrounding biome and produce self-sustaining populations - or in some cases,

\footnotetext{
${ }^{*}$ Corresponding author: shadmahlum@gmail.com
}

interbreed with existing wild conspecifics, thereby introducing deleterious domesticated genetic attributes into the wild population (Glover et al. 2017).

Over the last several decades, declines in wild Atlantic salmon Salmo salar populations have been reported throughout their historic range (Parrish et al. 1998, Friedland et al. 2003, Chaput 2012, Soto et al. 2018). During the same time period, there has been an increase in the production of domesticated S. salar (Gross 1998, Bostock et al. 2010). One of the biggest environmental challenges related to salmonid aquaculture is the escape of farmed individuals that disperse from cultivation sites and migrate into rivers to spawn (Taranger et al. 2015, Forseth et al. 2017). Retention of farmed fish within net pen facilities has greatly improved with time (Jensen et al.

(C) The authors 2019. Open Access under Creative Commons by Attribution Licence. Use, distribution and reproduction are unrestricted. Authors and original publication must be credited. 
2010), yet escape events still occur at levels that pose a significant threat to wild populations of salmon (see Wringe et al. 2018 for a recent example). To circumvent the ecological ramifications of escaped farmed salmon, various stakeholders have increased awareness and efforts to monitor the presence of escapees in wild populations (Glover et al. 2019) and to mitigate the effects that can occur between wild and farmed salmon.

Introgression of domesticated escapees is considered to be one of the most significant threats to native $S$. salar populations in countries where salmon aquaculture is practiced (Taranger et al. 2015, Forseth et al. 2017). This phenomenon has been documented in the wild for decades (Diserud et al. 2019, Glover et al. 2019), and extensive introgression and hybridization has been observed in areas where aquaculture and wild S. salar overlap (Clifford et al. 1998, Glover et al. 2013, Karlsson et al. 2016, Wringe et al. 2018). While consequences arising from escaped salmon are likely to be population-dependent (Fraser et al. 2010, Glover et al. 2013, Heino et al. 2015, Wringe et al. 2018), the offspring of domesticated salmon, and their hybrids with wild salmon, display reduced survival in the wild (McGinnity et al. 1997, Fleming et al. 2000, Skaala et al. 2012, 2019). Therefore, introgression of domesticated escapees in native $S$. salar populations, if extensive enough, may ultimately lead to the extirpation of vulnerable populations (McGinnity et al. 2003, Castellani et al. 2018). It is therefore imperative to be able to quantify escaped salmon in relation to specific populations so that management strategies (e.g. escapee removals and improved retention within net pens) can be implemented or improved to minimize the risk of further introgression. However, river systems where $S$. salar reside often encompass broad spatial scales that can be timeconsuming and costly to manually survey and difficult to attain a representative sample.

Quantifying escaped farmed salmon in a river can be challenging. Common survey techniques (e.g. mark-recapture or electrofishing) can incur undue stress on wild individuals at critical times in their life cycle (Snyder 2003), require releasing escaped salmon back into the system (e.g. mark-recapture), or are subject to limitations due to variation in the catch per unit effort (CPUE), which is beyond the changes in abundance (e.g. recreational fishing estimates; Maunder \& Punt 2004). Similar to other observational methods (e.g. video surveillance and camera traps), drift diving represents a relatively non-invasive method to directly survey the abundance of different species (Pilliod \& Peterson 2001, Ebner et al.
2015) in a range of habitat types (e.g. freshwater and marine ecosystems; St. John et al. 1990, Beauchamp et al. 1994, Toft et al. 2007), with extensive use in lotic ecosystems to monitor salmonids (Thurow et al. 2006, Orell et al. 2011, Vollset et al. 2014). Although drift diving has been used for several decades to assess salmonid populations in rivers, some concerns exist (Dolloff et al. 1996). For instance, the accuracy and precision of drift diving may vary according to various factors, such as individual fish size (Slaney \& Martin 1987, Hillman et al. 1992, Thurow et al. 2006), density across various habitats (Hankin \& Reeves 1988), habitat complexity (O'Neal 2007), and the tendency of individuals to seek specific habitat types (Orell \& Erkinaro 2007). Although visual estimates may incur uncertainties with regards to precision, drift dive estimates can save time and expenses (Dolloff et al. 1996, Thurow et al. 2006, Orell et al. 2011) and potentially increase the total habitat sampled, thus improving the overall abundance estimates of a system (Hankin \& Reeves 1988).

Drift diving is one of the main sampling methods used to quantify the number and proportion of escaped farmed $S$. salar throughout rivers in Norway (data from 133 rivers included in the national monitoring program in 2017; Glover et al. 2019). In order to identify farmed salmon escapees through drift diving, it is necessary to be able to distinguish them from wild conspecifics by identifying variations in several phenotypic traits (e.g. spotting patterns; Jørgensen et al. 2018). However, in contrast to other methods implemented in the Norwegian monitoring program that involve capture and subsequent determination of origin through scale reading, the accuracy of drift diving in differentiating between escaped farmed and wild salmon is still to be investigated. Therefore, the overall aim of this study was to (1) assess the accuracy of quantifying the proportion of escaped farmed salmon using the abundance approximations from drift diving validated against net captures, and (2) establish the accuracy of identifying escaped farmed salmon (i.e. true positive rate; TPR) in rivers during drift diving when applying commonly used removal methods (e.g. harpoon).

\section{MATERIALS AND METHODS}

This study consists of 2 independent datasets to assess the accuracy of drift diving in identifying escaped farmed salmon. Dataset 1 is a comparison of the proportion of escapees at sites observed during drift diving and subsequent net captures. Dataset 2 
quantifies the TPR of drift diving as a mitigation method to removed escapees from spawning sites.

\subsection{Study sites}

The rivers in which the methods were tested were located in 3 fjords in western Norway (Fig. 1). The rivers originate in alpine systems where steep gradients dominate the upper reaches of the watersheds and lower gradients dominate the lower reaches; hydropower is a prevalent feature in the landscape (6 of the 9 streams). Atlantic salmon Salmo salar and anadromous brown trout $S$. trutta represent the dominant salmonid species within the anadromous reaches of these rivers. The presence of aquaculture is variable among the 3 fjords with at least one National Salmon Fjord in each fjord complex that restricts aquaculture activities in these defined zones (Aasetre \& Vik 2013). The rivers were chosen based on the frequent observations of escaped farmed salmon in previous years, and because they were suitable for catching and sampling fish to validate drift diving counts.

Sampling occurred from 2016 to 2018 in October and November when salmon returned to spawn. To directly compare salmon drift dive estimates, each site needed to have stream conditions that were conductive to the use of a beach seine or gill nets (e.g.

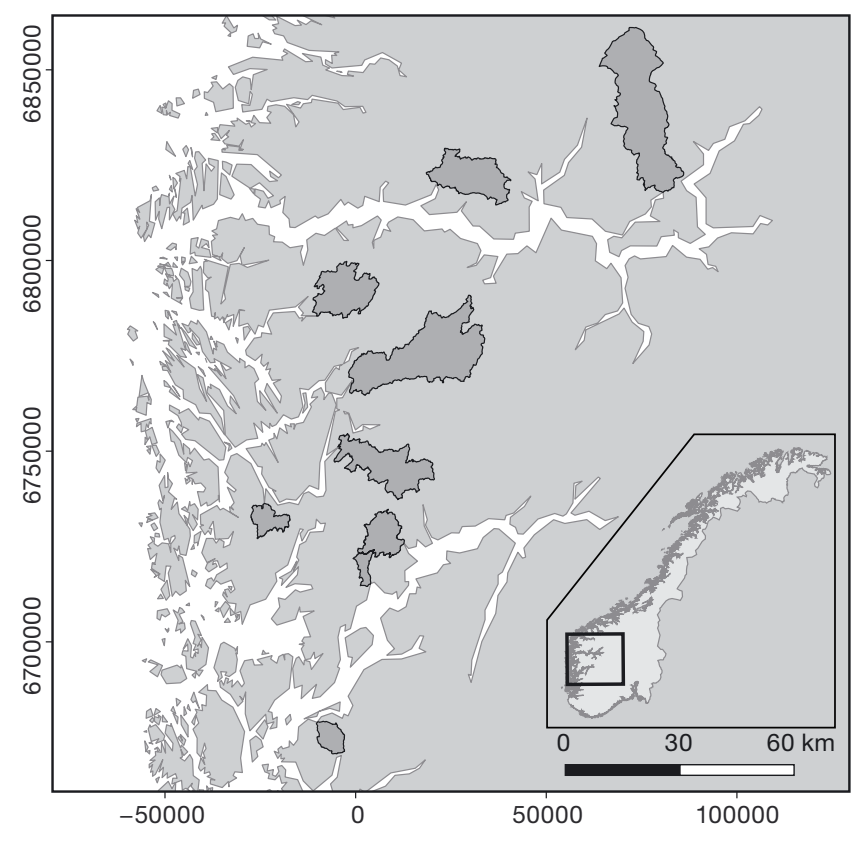

Fig. 1. Study area. Dark grey polygons: watersheds where comparison sampling occurred; black box: location in Norway (WGS84 / UTM zone 33N) low flow velocities and limited in-stream structures such as large boulders and large woody debris). A total of 26 comparisons were conducted at 19 different sites among 9 watersheds (Table 1). Capture sites consisted of pools ranging in size from 716 to $15179 \mathrm{~m}^{2}$ that were chosen based on previous experience indicating that these locations were spawning and/or holding pools for salmon. One site was excluded from the comparison analysis based on unrepresentative net captures $(<25 \%$ of the observed population during drift diving and an unequal CPUE towards escaped farmed salmon; Site 3 in Table 1).

\subsection{Dataset 1: drift diving and net captures}

Drift diving was conducted before the removal of fish (both wild and farmed) at a sampling site ( 10 to $15 \mathrm{~min})$. Prior to drift diving, underwater visibility (effective visibility; in m) was estimated as the distance at which features of the fish could be observed to assign the origin of the individual (e.g. wild vs. farmed). This was done by assessing objects with enough clarity to identify detailed characteristics (e.g. the facial features of a drift dive partner) and estimating the distance to those objects. A single downstream pass was used to count fish with experienced drift diving personnel, in accordance with Norwegian standards (NS 9456:2015). To maintain visual coverage of the stream width during sampling, the number of personnel (1 to 4 divers) was adjusted to the stream width and the effective visibility of the site. Only fish that passed upstream of the dive team were counted to avoid double counting of fish moving downstream. Upon encounter, fish were visually identified to species (i.e. S. salar or $S$. trutta), rearing origin (wild, hatchery, or farmed; see below), and size class (small: $<3 \mathrm{~kg}$; medium: 3 to $7 \mathrm{~kg}$; large: $>7 \mathrm{~kg}$ ). For the purposes of this study, the offspring of wild salmon produced and reared in a hatchery and deliberately released into the river as juveniles for the purpose of supportive breeding were classified as wild (identified by lack of adipose fin, which was removed prior to release as smolts). Morphological differences were used to distinguish between the different conspecifics. Specifically, escaped farmed $S$. salar were distinguished based on differences in body proportions, fin erosion, morphology of operculum, behavior, and pigmentation (Lund et al. 1991, Walker et al. 2006, Erkinaro et al. 2010, Jørgensen et al. 2018).

To remove salmon from the site immediately following drift diving, we used either gill nets (length = 
Table 1. Site, net captures, and drift dive observations of Atlantic salmon for each sampling year. First number: total captures; second number: total number of escaped farmed salmon (EFS). \%EFS $\mathrm{m}_{\mathrm{m}}$ mean proportion of escaped salmon for each year (bottom row) and site (column); bold \%EFS $\mathrm{m}_{\mathrm{m}}$ numbers indicate the mean for each method. Site 3 was removed from the overall analysis due to biased sampling during net captures

\begin{tabular}{|c|c|c|c|c|c|c|c|c|c|}
\hline \multirow[t]{2}{*}{ Site } & \multicolumn{4}{|c|}{-Net captures } & \multicolumn{4}{|c|}{-Drift dive } & \multirow{2}{*}{$\begin{array}{c}\text { Area } \\
\left(\mathrm{m}^{2}\right)\end{array}$} \\
\hline & 2016 & 2017 & 2018 & $\% \mathrm{EFS}_{\mathrm{m}}$ & 2016 & 2017 & 2018 & $\% \mathrm{EFS}_{\mathrm{m}}$ & \\
\hline \multicolumn{10}{|l|}{ Arnaelva } \\
\hline Site 1 & - & - & $13 / 3$ & 23.1 & - & - & $10 / 3$ & 30.0 & 1054 \\
\hline \multicolumn{10}{|l|}{ Åroyelva } \\
\hline Site 2 & $179 / 15$ & $267 / 9$ & $174 / 2$ & 4.3 & $186 / 7$ & $231 / 4$ & $196 / 6$ & 2.9 & 2482 \\
\hline Site 3 & - & - & $10 / 3$ & 30.0 & - & - & $45 / 3$ & 6.7 & 2894 \\
\hline \multicolumn{10}{|c|}{ Daleelva (Høyanger) } \\
\hline Site 4 & - & - & $4 / 1$ & 25.0 & - & - & $4 / 1$ & 25.0 & 716 \\
\hline Site 5 & - & - & $10 / 1$ & 10.0 & - & - & $12 / 1$ & 8.3 & 1254 \\
\hline Site 6 & $14 / 1$ & $7 / 0$ & $17 / 1$ & 5.3 & $15 / 1$ & $8 / 1$ & $23 / 1$ & 6.5 & 2016 \\
\hline Site 7 & $7 / 1$ & - & - & 14.3 & $11 / 2$ & - & - & 18.2 & 2283 \\
\hline Site 8 & - & $11 / 0$ & - & 0.0 & - & $15 / 0$ & - & 0.0 & 4603 \\
\hline Site 9 & $9 / 2$ & $4 / 0$ & - & 15.4 & $10 / 2$ & $5 / 0$ & - & 13.3 & 871 \\
\hline Site 10 & $8 / 1$ & - & - & 12.5 & $12 / 2$ & - & - & 16.7 & 760 \\
\hline Site 11 & - & $8 / 0$ & - & 0.0 & - & $9 / 0$ & - & 0.0 & 3042 \\
\hline \multicolumn{10}{|c|}{ Daleelva (Vaksdal) } \\
\hline Site 12 & $14 / 1$ & - & - & 7.1 & $28 / 2$ & - & - & 7.1 & 2905 \\
\hline Site 13 & $30 / 1$ & $30 / 0$ & $24 / 0$ & 1.1 & $34 / 1$ & $26 / 0$ & $31 / 0$ & 1.0 & 2803 \\
\hline \multicolumn{10}{|l|}{ Ekso } \\
\hline Site 14 & - & - & $17 / 0$ & 0.0 & & & $18 / 2$ & 11.1 & 15179 \\
\hline Site 15 & - & $49 / 2$ & - & 4.1 & - & $54 / 2$ & - & 3.7 & 6609 \\
\hline \multicolumn{10}{|c|}{ Matreelva } \\
\hline Site 16 & - & - & $9 / 2$ & 22.2 & - & - & $9 / 2$ & 22.2 & 1236 \\
\hline \multicolumn{10}{|c|}{ Steinsdalselva } \\
\hline Site 17 & - & - & $5 / 1$ & 20.0 & - & - & $5 / 1$ & 20.0 & 1794 \\
\hline \multicolumn{10}{|c|}{ Strandadalselva } \\
\hline Site 18 & - & - & $10 / 0$ & 0.0 & - & - & $11 / 0$ & 0.0 & 1500 \\
\hline \multicolumn{10}{|c|}{ Uskedalselva } \\
\hline Site 19 & $18 / 0$ & - & - & 0.0 & $18 / 0$ & - & - & 0.0 & 1035 \\
\hline$\% \mathrm{EFS}_{\mathrm{m}}$ & 9.4 & 1.1 & 12.5 & 8.5 & 9.4 & 2.6 & 11.9 & 8.6 & \\
\hline
\end{tabular}

$30 \mathrm{~m}$, depth $=2 \mathrm{~m}$, half mesh size $=45$ to $75 \mathrm{~mm}$ ), a beach seine (length $=40 \mathrm{~m}$, depth $=6 \mathrm{~m}$, half mesh size $=15 \mathrm{~mm}$ ), or both during the capture process (referred to as net captures throughout). All nets were constructed of nylon. Prior to drift diving, the net was positioned at the back of the pool to prevent individuals from escaping downstream during drift diving. Once drift dive transects were completed, several personnel guided salmon into position to encircle them with the net. To limit accidental escape after capture, entanglement with the net, and to reduce stress during sampling, fish were removed from the capture area and placed in holding cages until processing $(30 \mathrm{~mm}$ half mesh nylon; $100 \times 50 \times$ $50 \mathrm{~cm}$ ). For each individual, we measured total length $(\mathrm{cm})$, sex, noted the presence of an adipose fin, and collected scales to determine the origin (described below). Fish identified as farmed escapees were killed upon capture, as the work, in part, was organized to reduce the incidence of farmed fish in the populations. In sites with more than 50 captured individuals, Finquel vet. $\left(100 \mathrm{mg} \mathrm{l}^{-1}\right)$ was used to sedate the fish during workups; they were then placed in the cages to recover from the anesthetic (10 to $15 \mathrm{~min}$ from anesthetization to release).

In addition to comparing relative abundance of escapees between the 2 methods, we also assessed the accuracy of drift diving to differentiate among size classes. Correct size classification of salmon is important when assessing the impact of farmed fish, as fecundity is strongly sizedependent (Fleming 1996). Because no weights were taken and due to a lack of length-weight regressions specific to the different populations sampled, we categorized size classes of net captures based on the sea winter age (calculated from scale reading; SW) and length of wild $S$. salar caught in the net. We classified the SW stages as 1, 2, and 3+ SW age classes. Then, we calculated the 25 and $75 \%$ quartile (interquartile range; IQR) of length for each SW and divided the difference in length of the IQR between adjacent SW by 2 . This created breaks at $70.5 \mathrm{~cm}$ between 1 and $2 \mathrm{SW}$ fish and $88.5 \mathrm{~cm}$ for 2 and 3+ SW fish (horizontal lines in Fig. 2). To compare to drift dive size classifications, net-captured salmon $<70.5 \mathrm{~cm}$ were classified as small, 70.5 to $88.5 \mathrm{~cm}$ were classified as medium, and $>88.5 \mathrm{~cm}$ were classified as large.

\subsection{Dataset 2: removal of escaped farmed salmon during drift diving surveys}

A secondary independent dataset was incorporated to supplement the study and to compare the TPR (proportion of positively identified farmed 


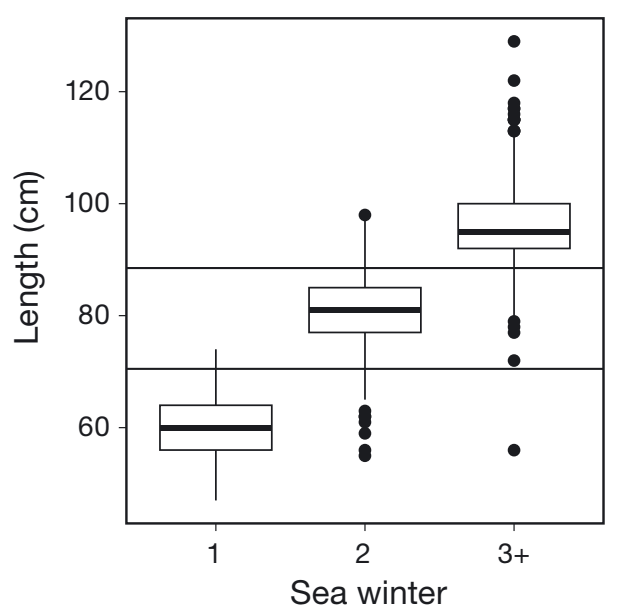

Fig. 2. Size classification of Atlantic salmon net captures based on sea winter age. Solid horizontal lines: length breaks into small, medium, and large size classifications. Boxes: interquartile range (IQR); horizontal lines in the boxes: median values; whiskers: 1.5 times the IQR ; solid circles: outliers

escaped salmon) of identifying escapees during routine removals of escapees from rivers with drift diving. Significant resources are diverted throughout Norway to mitigate potential introgression with wild fish, and drift diving is one method used to identify and actively remove escaped farmed salmon from the watercourse where introgression is prone to occur. Removals included in this study are located throughout western Norway among 35 rivers (8 of 9 rivers from data set 1) and involved data from 2016 to 2018. Consistent with drift diving protocols described above, the removals were carried out by the Norwegian Research Center (NORCE). Once visually identified as farmed escaped salmon, harpoons were used to remove individuals. The total length $(\mathrm{cm})$, wet mass $(\mathrm{kg})$, sex, and maturity stage (visual inspection of gonads) were recorded, and scale samples were collected to confirm the individual was of aquaculture origin.

\subsection{Origin classification based on scale readings}

To verify the visual identity of each fish captured with nets and removed with harpoons, scales were taken just posterior of the dorsal fin directly above the lateral line. Origin was based on variations of seasonal growth rings as described in Fiske et al. (2005). Consistent with Diserud et al. (2019), the origin for net-captured individuals with unidentifiable scales was based on visual identification at capture $(\mathrm{n}=46$; see Table 2). Individuals with missing or un- readable scales from dataset 2 were removed when calculating the TPR ( $\mathrm{n}=2$; see Table 2$)$. Scale readings were performed by NORCE, the Institute of Marine Research, and Rådgivende Biologer AS.

\subsection{Analysis}

We first used a generalized linear model (Poisson error) to regress the abundances of the 2 methods to determine their precision and any indication of unwanted bias (e.g. outliers signifying an unrepresentative sample for either method). To account for left skewedness of the data distribution, relative abundances were log transformed. A strong relationship with small variance would indicate that the methods had equivalent performances when sampling the populations of interest, and deviations would indicate a potential sampling bias between the 2 methods. A Bayesian inference was implemented to compare the proportion for each size category (small, medium, large) and the proportion of farmed escapees observed between drift diving (explanatory variable) and net captures (response variable). No information was available for a prior distribution for the Bayesian inference; therefore, we used a diffuse normal prior for the intercept and slope (uninformative). Because of violations of model assumptions (non-normally distributed residuals), the failure of model outputs with a binomial distribution to fit the data, and an expected linear relationship between methods, we deferred to a Gaussian distribution instead of the preferred binomial distribution for proportion data. Furthermore, to control for the impact of increased deviations in the proportion of farmed escapees at sites with small counts, we weighted each sample by the sample size of net captures, thereby giving more weight to larger catches. We ran 5000 burn-in iterations across 3 chains before running the 15000 Markov chain Monte Carlo samplings (45000 total iterations). Model convergence was achieved based on the low variance between chains (Gelman-Rubin diagnostic test $<1.05$; Gelman \& Rubin 1992) and visual inspection of the posterior distributions. In addition, 2 data points indicated a large difference in the proportion of farmed escapees between the 2 methods (extreme outliers). Therefore, we compared the goodness-of-fit (adj. $r^{2}$ ) of the model that included all sampling points (primary model) and a model excluding the 2 data points which were believed to be outside the ability to accurately identify and quantify individuals at a site (i.e. observed escape of salmon during capture from the 
Table 2. Net captures, drift dive observations, and harpoon removals of Atlantic salmon. Rearing origin was determined from scale readings, and individuals were classified as wild (W), escaped (E), or unknown (U). Scales were classified as unknown if they were missing, damaged, or new (i.e. lacking an entire growth cycle). Size was categorized by weight for drift diving (small [S]: $<3 \mathrm{~kg}$; medium [M]: 3 to $7 \mathrm{~kg}$; large [L]: $>7 \mathrm{~kg}$ ) and by mean length $(\mathrm{cm})$ for net captures and harpoon removals

\begin{tabular}{|c|c|c|c|c|c|c|c|c|c|c|c|}
\hline & \multirow[t]{2}{*}{ Total } & \multicolumn{3}{|c|}{ Rearing origin } & \multicolumn{3}{|c|}{ Size } & \multicolumn{2}{|c|}{ Sex } & \multicolumn{2}{|c|}{ Mature } \\
\hline & & W & $\mathrm{E}$ & $\mathrm{U}$ & & & & $M$ & $\mathrm{~F}$ & Yes & No \\
\hline \multicolumn{2}{|c|}{ Drift diving } & & & & $\mathrm{S}$ & $\mathrm{M}$ & $\mathrm{L}$ & & & & \\
\hline 2016 & 314 & 297 & 17 & - & 36 & 169 & 109 & - & - & - & - \\
\hline 2017 & 348 & 241 & 7 & - & 43 & 177 & 128 & - & - & - & - \\
\hline 2018 & 364 & 344 & 20 & - & 83 & 160 & 121 & - & - & - & - \\
\hline \multicolumn{12}{|l|}{ Seine } \\
\hline 2016 & 279 & 252 & 21 & 6 & & 84 & & 98 & 179 & - & - \\
\hline 2017 & 376 & 352 & 11 & 13 & & 86 & & 137 & 239 & - & - \\
\hline 2018 & 288 & 250 & 13 & 25 & & 82 & & 151 & 137 & - & - \\
\hline \multicolumn{12}{|c|}{ Harpoon } \\
\hline 2016 & 91 & 0 & 89 & 2 & & 78 & & 50 & 40 & 66 & 25 \\
\hline 2017 & 48 & 0 & 48 & 0 & & 77 & & 25 & 20 & 38 & 9 \\
\hline 2018 & 46 & 1 & 45 & 0 & & 75 & & 29 & 17 & 42 & 4 \\
\hline
\end{tabular}

site; open circles in Fig. 5). All analyses were done within the statistical programs R v.3.5.2 (R Core Team 2018) and JAGS v.4.3.0 (Plummer 2003).

\section{RESULTS}

A total of 1026 salmon were counted and identified through drift diving; of these, 943 were subsequently captured and verified through scale analysis (Table 2). Among the captured individuals, 45 were classified as true escaped farmed salmon and 854 were classified as true wild salmon based on the results from the scale analysis (Table 2). The origin of the 44 individuals with unreadable scales was determined by visual identification. For individuals whose origin could be verified during scale readings, the accuracy of the visual identification on land for net captures was very high (96 and 99\% for farmed escaped and wild origin, respectively).

\subsection{Dataset 1: drift diving and net captures}

Comparison of the abundances between the 2 methods demonstrated that drift diving and net captures were very highly correlated $\left(\mathrm{r}^{2}=0.99\right.$; Fig. 3) with a near 1:1 relationship between the methods (slope $=1.06, z=37.202, \mathrm{n}=25, \mathrm{p}<0.001$; Fig. 3). The overall trend showed that net captures of Atlantic salmon were lower compared to drift dive counts of Atlantic salmon, which was likely due to difficulties in obtaining all fish in a site, as some fish were observed to escape during capture attempts.

Overall, drift diving classified salmon into different size categories relatively well compared to net captures (small: adj. $\mathrm{r}^{2}=0.5$; medium: adj. $\mathrm{r}^{2}=0.37$; large: adj. $\mathrm{r}^{2}=0.55$ ) with no significant deviation from the expected 1:1 relationship (small: mean $=0.96$, lower $\mathrm{CI}=$ 0.75 , upper $\mathrm{CI}=1.16$; medium: mean $=$ 1.27, lower $\mathrm{CI}=0.85$, upper $\mathrm{CI}=1.7$; large: mean $=1.03$, lower $\mathrm{CI}=0.88$, upper $\mathrm{CI}=1.18$; Fig. 4).

The proportion of farmed escapees estimated from drift diving and net captures was also well correlated (adj. $\mathrm{r}^{2}=$ 0.79 ; Fig. 5a) with a significant relationship between the 2 methods (mean = 0.77, lower $\mathrm{CI}=0.52$, upper $\mathrm{CI}=1.01$ ). Furthermore, no statistical difference was seen between a 1:1 relationship and the current predicted relationship (dashed line in Fig. 5a). However, $97 \%$ of the values of the posterior distribution fell below a 1:1 relationship, suggesting that a small difference potentially exists between drift diving and net captures. This was further supported after removing the 2 outliers, where we observed an improved goodness-of-fit for the model (adj. $\mathrm{r}^{2}=0.93$; mean $=0.85$, lower $\mathrm{CI}=0.64$, upper $\mathrm{CI}=1.06$; Fig. $5 \mathrm{~b}$ ) and a high proportion $(92 \%)$ of the posterior distribution below the expected 1:1 trend line.

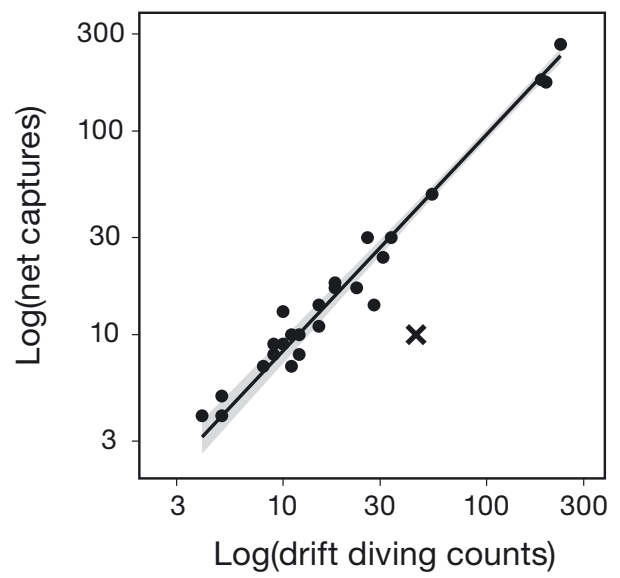

Fig. 3. Generalized linear regression of the total Atlantic salmon counts observed in drift diving and net captures. Solid line: fitted line; shaded area: $95 \%$ confidence intervals. The $x$ is a point that was removed from the analysis due to an unrepresentative and biased net capture 

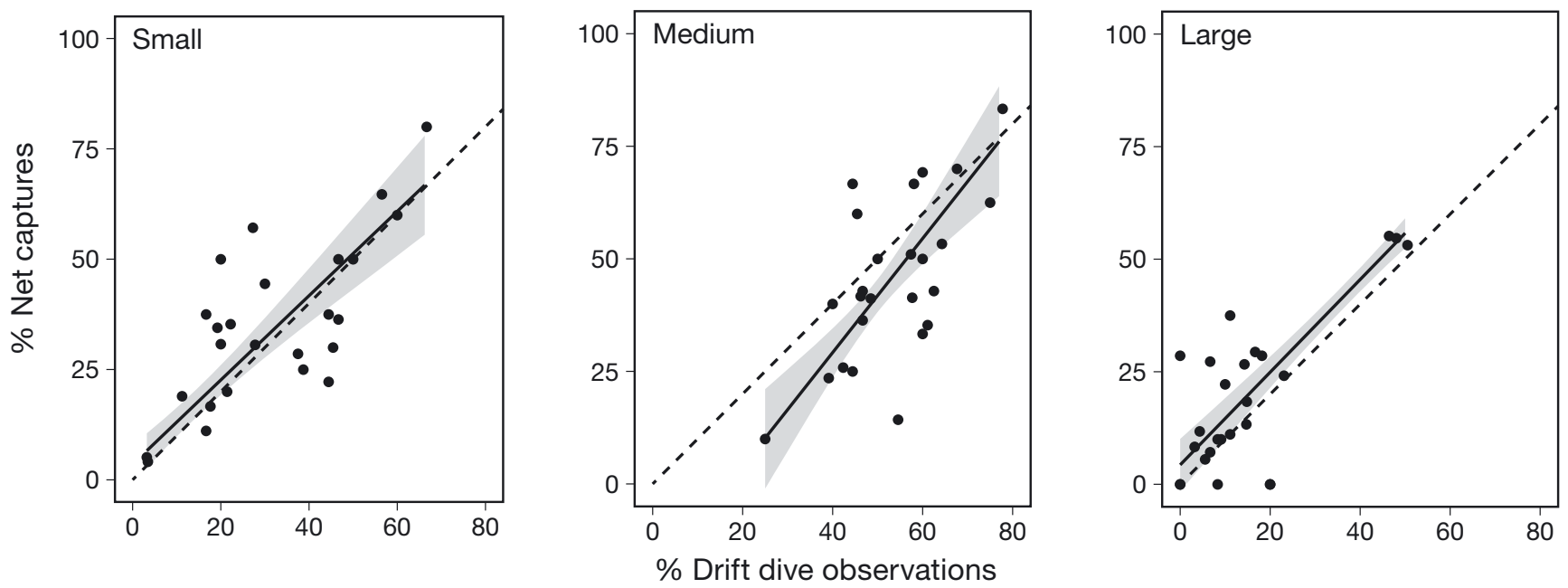

Fig. 4. Comparison of the proportion of size categories (small, medium, and large) of Atlantic salmon between drift diving and net captures. Solid line: fitted line; dashed lines: 1:1 line; shaded areas: $95 \%$ credibility intervals
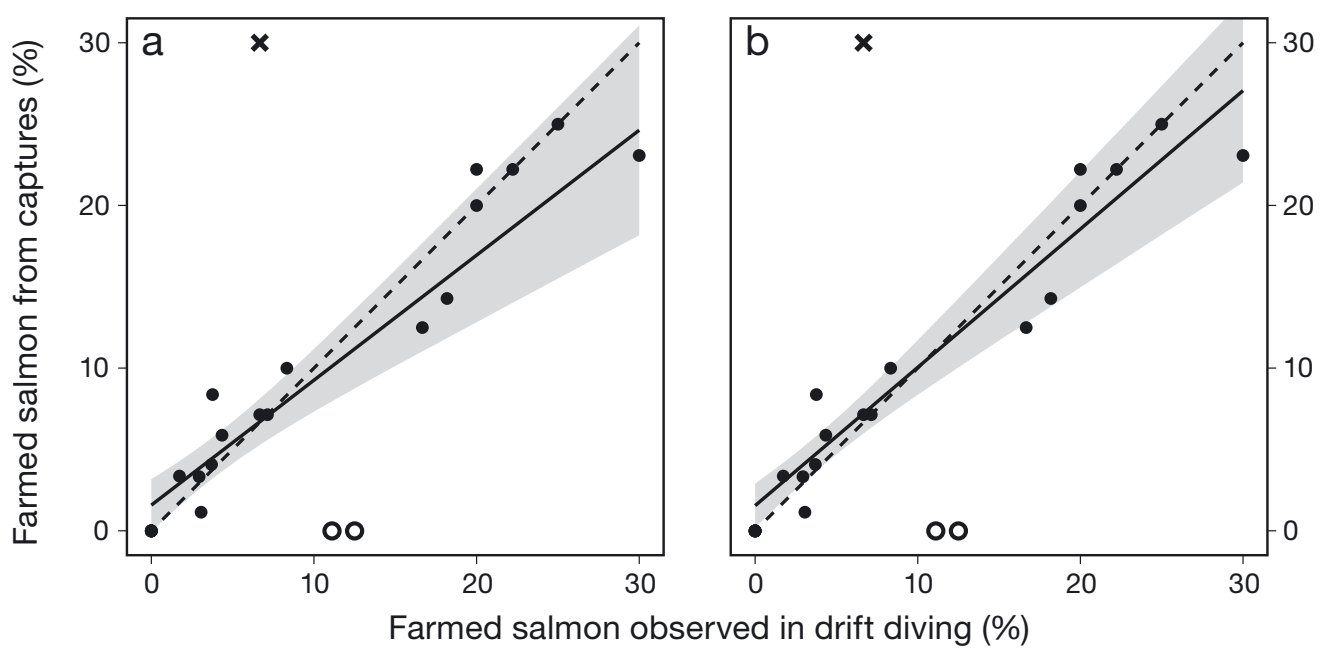

Fig. 5. (a) Bayesian inference comparing the proportion of escaped Atlantic salmon observed in drift diving and captured with nets; (b) the same relationship after removing 2 outliers (open circles). Solid line: fitted line; dashed line: 1:1 relationship; shaded area: $95 \%$ credibility intervals (CI). Fitted line and CIs were calculated from all points - solid and open circles in (a) (adj. $\mathrm{r}^{2}=$ 0.79). Outliers removed due to limitations outside of individual identification; e.g. escape during net capture (b) (adj. $\left.\mathrm{r}^{2}=0.93\right)$. The $\mathrm{x}$ in both panels indicates a point that was removed from the analysis due to an unrepresentative and biased net capture

\subsection{Dataset 2: removal of escaped farmed salmon during drift diving surveys}

Independent drift diving sampling of 35 rivers during routine removals of farmed salmon escapees identified 185 individuals as escapees (Table 2). Scale analysis verified that 182 were indeed escapees (TPR $=98 \%$ ) and 1 individual was identified as a wild S. salar. Two individuals had unreadable scales and could not be verified as either escaped or wild.

\section{DISCUSSION}

Accurate identification is pivotal when monitoring proportions of farmed salmon escapees in rivers and assessing the effectiveness of mitigation efforts against the potential interbreeding of domesticated conspecifics (e.g. improved aquaculture retention and removal efforts). Here, for the first time, we validated that drift diving represents a robust method that can accurately classify Atlantic salmon Salmo 
salar into size categories and determine their origin (i.e. wild vs. farmed). Furthermore, results from individual removal data $(\mathrm{TPR}=98 \%$ with harpoon captures) demonstrates that drift divers rarely identified wild fish as escaped farmed salmon (1 out of 183 individuals). Similar to previous studies (Orell \& Erkinaro 2007, Orell et al. 2011), we also found drift dive abundances to be highly correlated with net captures of Atlantic salmon, even at large densities (>150 ind.). Based on these findings, we conclude that drift diving represents a robust method, when observation conditions are adequate, to effectively assess the numbers, size categories, and proportions of farmed vs. wild $S$. salar.

While previous studies on drift diving quantified the number of $S$. salar, few have evaluated the precision of this method to quantify differences in population structure (but see Orell \& Erkinaro 2007 as an example of distinguishing between sex of $S$. salar) and particularly, the identification of farmed escaped salmon in rivers. In general, there was a good fit between the proportions of escapees identified between the 2 methods (adj. $\mathrm{r}^{2}=0.79$ ), demonstrating that visual identification of escapees by snorkeling was, in most cases, highly accurate. However, some deviation from the expected relationship was observed, likely caused by biases in either of the sampling methods. Firstly, some error is likely to arise due to limitations in catch efficiency of net captures. For instance, we were unable to verify that all individuals were captured at a site, as some fish escaped during net captures. For example, small $1 \mathrm{SW}$ fish $(<50 \mathrm{~cm})$ were, in some cases, observed to swim through or under the net and are therefore likely to be underrepresented in those catches. Because we were unable to verify the origin of missed individuals, these were not included in the calculations of proportions and hence could potentially result in the differences observed between drift diving and net captures. Furthermore, degraded scale quality limited our ability to verify the origin of some individuals. Finally, many of the sample locations had relatively few fish $(<20$ ind. observed in 18 of 26 locations). Consequently, small deviations in counts between the 2 methods will, in such cases, create large discrepancies in the observed proportions.

Secondly, some deviance from the 1:1 relationship in the present study may arise due to identification error during drift diving. As characterizations of farmed salmon escapees during snorkeling is based on visual identifications, it requires that the snorkeler is able to observe each fish well enough to correctly distinguish escapees and wild fish. This likely de- pends upon several factors, such as visual conditions underwater (i.e. water clarity and light conditions), the distance between the observer and the fish, the length of time the observer has to observe each fish, and the experience of the observer. Furthermore, farmed fish may vary in distinctiveness, with the typical 'farmed' features being more expressed in some individuals than in others. For example, fish that escape as smolts are likely to have fewer distinguishing characteristics than recently escaped fish and may thus be more difficult to differentiate from wild fish (Jørgensen et al. 2018). Also, repeat spawners of wild fish may, in some cases, exhibit abrasions and fin erosion commonly seen in farmed escaped salmon (Fleming et al. 1997) and be miss-identified as escapees, particularly by inexperienced observers. However, in those instances where escapees were removed and verified with scale analysis (dataset 2), only 1 wild fish was misidentified as a domesticated salmon, indicating that such misidentification of previously spawned salmon are rare. Yet in most cases, identification error is likely to be towards misidentifications of farmed fish as wild fish, and consequently, cause an underestimation of the proportion of farmed salmon escapees in the sample or river. This was not apparent in our study, and in fact, drift diving appeared to potentially overestimate the proportion of farmed fish compared to the net catches, as $97 \%$ of the posterior distribution fell below the predicted 1:1 line for the comparison of the 2 methods. Still, for most locations, both the total number and proportion of farmed fish coincided well between the 2 methods and, while some bias may be present, it will likely have little effect on the overall management decisions.

Drift diving has only recently (since 2014) been included as a standard method used in the Norwegian monitoring program of farmed escaped salmon (Glover et al. 2019), supplementing the traditional method based on validation of fish gathered from angling (Diserud et al. 2019, Glover et al. 2019). Compared to angling-based methods of assessing the number and proportions of farmed escaped salmon (e.g. net captures and fishing), drift diving offers several advantages. For example, the variation in the CPUE is one of the main challenges when incorporating fishing statistics to quantify farmed escaped salmon. In Norway, fishing for $S$. salar primarily occurs during summer when salmon enter the river or are holding in estuaries until optimal stream conditions for upstream migration (e.g. adequate water discharge). This could result in a mismatch between sampling and the effective spawning population 
(Harvey et al. 2017). It has also been shown that the angling catch efficiency is quickly reduced after river entry (Harvey et al. 2017), suggesting that variation in time of river entry (Erkinaro et al. 2010, Svenning et al. 2017) may cause different catch probabilities between wild and escaped salmon.

Furthermore, differences within the river in the distribution of escaped and wild salmon and variations in spatial CPUE during fishing may further underestimate or overestimate the proportion of escaped farmed salmon in the spawning populations (Moe et al. 2016). For example, sampling in areas where escapees or wild fish are spatially aggregated may give a biased sample. In addition, without prior knowledge of the spatial distribution of the fish in the river, it is almost impossible to know how to design a representative sampling design. Drift diving, on the other hand, is less susceptible to many of these issues. For instance, the spatial CPUE is less variable during drift diving when the entire anadromous reach ( 5 to $10 \mathrm{~km})$ of moderately sized rivers can be sampled in a single day with 1 to 3 divers. Because of the quick assessment of the river and the downstream direction of the sampling, drift diving can also capture differences in distribution between conspecifics while minimizing effects from fluctuations in population density during sampling (e.g. immigration or emigration). Finally, drift diving estimates are usually conducted close to or during active spawning and therefore the mismatch between sampling and effective spawning population is limited and can provide a better representation of the proportion of farmed escaped salmon in the period that is most relevant in terms of risk for genetic effects on the population (i.e. spawning).

Another important advantage of drift diving is the relatively limited time and expense needed to sufficiently survey broad spatial extents (Dolloff et al. 1996, Thurow et al. 2006, Orell et al. 2011). For instance, to obtain a comparable sample with net captures for this study, additional time (on average 1 to $2 \mathrm{~h}$ ), personnel (5 to 7 ), and equipment (e.g. capture nets, holding pens) were needed to capture the same representative sample that took 2 divers only 10 to $15 \mathrm{~min}$ to sample. In addition, drift divers are able to sample habitats that are impractical to sample with conventional methods or are prohibited (e.g. streams that are closed to fishing). Drift diving is also less invasive compared to other methods that would require the physical removal of the individual to determine whether it was an escaped or wild salmon.

While the current study provided valuable information on the accuracy of drift dive estimates to quantify farmed escaped salmon, limitations exist. Orell et al. (2011) saw a decrease in the precision of drift diving estimates of $S$. salar abundance when assessing more complex habitats. While routine sampling of the spawning population includes a range of conditions in terms of river size, depth, and water clarity, we focused on sites that allowed for a congregation of salmon while also allowing for the use of net captures to validate observations. This necessitated us to focus predominantly on habitat units consisting of pools. As a result, it is likely that estimates and the ability to identify farmed escaped salmon will fluctuate as habitat complexity (e.g. riffle vs. pools or the inclusion of boulders and debris) and sampling conditions (e.g. water turbidity and clarity) vary. Furthermore, while not assessed in this study, the experience of the diver is an important factor in being able to distinguish between conspecifics (Orell et al. 2011), and it is necessary to develop training protocols to improve the skill level of inexperience personnel while maintaining the integrity of the sampling method.

In conclusion, the implementation of drift diving in rivers where escaped farmed and wild $S$. salar coexist was determined to be a robust tool that will allow managers to quickly and accurately identify areas of potential introgression and focus removal efforts. This study demonstrates the usefulness to assess the proportion of escaped farmed salmon in a system via drift diving and provides stakeholders with a valuable tool that is not limited by changes in CPUE nor does it inflict unnecessary stress at a sensitive time in a salmon's life history (e.g. spawning). Future applications should focus on assessing how changes in habitat affect the accuracy of correctly identifying escaped salmon.

Acknowledgements. Thanks to R. Lennox from NORCE and S. Knutar and L. Unneland from The Institute of Marine Research who helped with the acquisition of data or input of earlier drafts of this manuscript. Primary funding was available through the Norwegian national monitoring program for escaped farmed salmon.

\section{LITERATURE CITED}

Aasetre J, Vik J (2013) Framing the environment-disputes and developments in the management of Norwegian salmon fjords. Ocean Coast Manage 71:203-212

Beauchamp DA, Byron ER, Wurtsbaugh WA (1994) Summer habitat use by littoral zone fishes in Lake Tahoe and the effects of shoreline structures. N Am J Fish Manage 14: 385-394

Bostock J, McAndrew B, Richards R, Jauncey K and others (2010) Aquaculture: global status and trends. Philos Trans R Soc B 365:2897-2912 
Castellani M, Heino M, Gilbey J, Araki H, Svåsand T, Glover KA (2018) Modeling fitness changes in wild Atlantic salmon populations faced by spawning intrusion of domesticated escapees. Evol Appl 11:1010-1025

* Champagnon J, Elmberg J, Guillemain M, Gauthier-Clerc M, Lebreton JD (2012) Conspecifics can be aliens too: a review of effects of restocking practices in vertebrates. J Nat Conserv 20:231-241

* Chaput G (2012) Overview of the status of Atlantic salmon (Salmo salar) in the North Atlantic and trends in marine mortality. ICES J Mar Sci 69:1538-1548

Clifford SL, McGinnity P, Ferguson A (1998) Genetic changes in Atlantic salmon (Salmo salar) populations of northwest Irish rivers resulting from escapes of adult farm salmon. Can J Fish Aquat Sci 55:358-363

Diserud OH, Fiske P, Sægrov H, Urdal K and others (2019) Escaped farmed Atlantic salmon in Norwegian rivers during 1989-2013. ICES J Mar Sci 76:1140-1150

Dolloff A, Kershner J, Thurow R (1996) Underwater observation. In: Murphy BR, Willis DW (eds) Fisheries techniques, 2nd edn. American Fisheries Society, Bethesda, MD, p 533-554

Ebner BC, Fulton CJ, Cousins S, Donaldson JA, Kennard MJ, Meynecke JO, Schaffer J (2015) Filming and snorkelling as visual techniques to survey fauna in difficult to access tropical rainforest streams. Mar Freshw Res 66:120-126

Erkinaro J, Niemelä E, Vähä JP, Primmer CR, Brørs S, Hassinen E (2010) Distribution and biological characteristics of escaped farmed salmon in a major subarctic wild salmon river: implications for monitoring. Can J Fish Aquat Sci 67:130-142

Fiske P, Lund RA, Hansen LP (2005) Identifying fish farm escapees. In: Cadrin SX, Friedland KD, Waldman JR (eds) Stock identification methods: application in fishery science. Elsevier, New York, NY, p 659-680

Fleming IA (1996) Reproductive strategies of Atlantic salmon: ecology and evolution. Rev Fish Biol Fish 6:379-416

Fleming IA, Lamberg A, Jonsson B (1997) Effects of early experience on the reproductive performance of Atlantic salmon. Behav Ecol 8:470-480

Fleming IA, Hindar K, Mjölneröd IB, Jonsson B, Balstad T, Lamberg A (2000) Lifetime success and interactions of farm salmon invading a native population. Proc R Soc B 267:1517-1523

Forseth T, Barlaup BT, Finstad B, Fiske P and others (2017) The major threats to Atlantic salmon in Norway. ICES J Mar Sci 74:1496-1513

Fraser DJ, Minto C, Calvert AM, Eddington JD, Hutchings JA (2010) Potential for domesticated-wild interbreeding to induce maladaptive phenology across multiple populations of wild Atlantic salmon (Salmo salar). Can J Fish Aquat Sci 67:1768-1775

Friedland KD, Reddin DG, McMenemy JR, Drinkwater KF (2003) Multidecadal trends in North American Atlantic salmon (Salmo salar) stocks and climate trends relevant to juvenile survival. Can J Fish Aquat Sci 60:563-583

Gelman A, Rubin DB (1992) Inference from iterative simulation using multiple sequences. Stat Sci 7:457-472

* Glover KA, Soldberg MF, McGinnity P, Hindar K and others (2017) Half a century of genetic interaction between farmed and wild Atlantic salmon: status of knowledge and unanswered questions. Fish Fish 18:890-927

Glover KA, Pertoldi C, Besnier F, Wennevik V, Kent M, Skaala $\varnothing$ (2013) Atlantic salmon populations invaded by farmed escapees: quantifying genetic introgression with a Bayesian approach and SNPs. BMC Genet 14:74

Glover KA, Urdal K, Næsje T, Skoglund H and others (2019) Domesticated escapees on the run: the second-generation monitoring programme reports the numbers and proportions of farmed Atlantic salmon in >200 Norwegian rivers annually. ICES J Mar Sci 76:1151-1161

Gross MR (1998) One species with two biologies: Atlantic salmon (Salmo salar) in the wild and in aquaculture. Can J Fish Aquat Sci 55:131-144

Hankin DG, Reeves GH (1988) Estimating total fish abundance and total habitat area in small streams based on visual estimation methods. Can J Fish Aquat Sci 45: 834-844

* Harvey AC, Tang Y, Wennevik V, Skaala Ø, Glover KA (2017) Timing is everything: fishing season placement may represent the most important angling induced evolutionary pressure on Atlantic salmon populations. Ecol Evol 7:7490-7502

* Heino M, Svåsand T, Wennevik V, Glover KA (2015) Genetic introgression of farmed salmon in native populations: quantifying the relative influence of population size and frequency of escapees. Aquacult Environ Interact 6: $185-190$

*Hillman TW, Mullan JW, Griffith JS (1992) Accuracy of underwater counts of juvenile Chinook salmon, coho salmon, and steelhead. N Am J Fish Manage 12:598-603

Jensen Ø, Dempster T, Thorstad EB, Uglem I, Fredheim A (2010) Escapes of fishes from Norwegian sea-cage aquaculture: causes, consequences and prevention. Aquacult Environ Interact 1:71-83

Jørgensen KM, Soldberg MF, Besnier F, Thorsen A and others (2018) Judging a salmon by its spots: environmental variation is the primary determinant of spot patterns in Salmo salar. BMC Ecol 18:14

KKarlsson S, Diserud OH, Fiske P, Hindar K (2016) Widespread genetic introgression of escaped farmed Atlantic salmon in wild salmon populations. ICES J Mar Sci 73: 2488-2498

Lund RA, Økland F, Hansen LP (1991) Farmed Atlantic salmon (Salmo salar) in fisheries and rivers in Norway. Aquaculture 98:143-150

Maunder MN, Punt AE (2004) Standardizing catch and effort data: a review of recent approaches. Fish Res 70:141-159

McGinnity P, Stone C, Taggart JB, Cooke D and others (1997) Genetic impact of escaped farmed Atlantic salmon (Salmo salar L.) on native populations: use of DNA profiling to assess freshwater performance of wild, farmed, and hybrid progeny in a natural river environment. ICES J Mar Sci 54:998-1008

McGinnity P, Prodöhl P, Ferguson A, Hynes R and others (2003) Fitness reduction and potential extinction of wild populations of Atlantic salmon, Salmo salar, as a result of interactions with escaped farm salmon. Proc R Soc B 270: 2443-2450

*Moe K, Næsje TF, Haugen TO, Ulvan EM, Aronsen T, Sandnes T, Thorstad EB (2016) Area use and movement patterns of wild and escaped farmed Atlantic salmon before and during spawning in a large Norwegian river. Aquacult Environ Interact 8:77-88

Naylor RL, Williams SL, Strong DR (2001) Aquaculturea gateway for exotic species. Science 294:1655-1656

O'Neal JS (2007) Snorkel surveys. Salmonid field protocols handbook. American Fisheries Society, Bethesda, MD

Orell P, Erkinaro J (2007) Snorkelling as a method for assess- 
ing spawning stock of Atlantic salmon, Salmo salar. Fish Manag Ecol 14:199-208

Orell P, Erkinaro J, Karppinen P (2011) Accuracy of snorkelling counts in assessing spawning stock of Atlantic salmon, Salmo salar, verified by radio tagging and underwater video monitoring. Fish Manag Ecol 18:392-399

Parrish DL, Behnke RJ, Gephard SR, McCormick SD, Reeves GH (1998) Why aren't there more Atlantic salmon (Salmo salar)? Can J Fish Aquat Sci 55:281-287

Pilliod DS, Peterson CR (2001) Local and landscape effects of introduced trout on amphibians in historically fishless watersheds. Ecosystems 4:322-333

Plummer M (2003) JAGS: a program for analysis of Bayesian graphical models using Gibbs sampling. In: Hornik K, Leisch F, Zeileis A (eds) Proceedings of the $3^{\text {rd }}$ international workshop on distributed statistical computing (DSC 2003), 20-22 March 2003, Vienna. R Foundation for Statistical Computing, Vienna

R Core Team (2018) R: a language and environment for statistical computing. R Foundation for Statistical Computing, Vienna

Skaala Ø, Besnier F, Borgström R, Barlaup B and others (2019) An extensive common garden study with domesticated and wild Atlantic salmon in nature reveals impact on smolt production and shifts in fitness traits. Evol Appl 12:1001-1016

Skaala $\varnothing$, Glover KA, Barlaup BT, Svåsand T, Besnier F, Hansen MM, Borgstrøm R (2012) Performance of farmed, hybrid, and wild Atlantic salmon (Salmo salar) families in a natural river environment. Can J Fish Aquat Sci 69: 1994-2006

Slaney PA, Martin AD (1987) Accuracy of underwater census of trout populations in a large stream in British Columbia. N Am J Fish Manage 7:117-122

Snyder DE (2003) Invited overview: conclusions from a review of electrofishing and its harmful effects on fish. Rev Fish Biol Fish 13:445-453

Soto DX, Trueman CN, Samways KM, Dadswell MJ, Cunjak RA (2018) Ocean warming cannot explain synchronous

Editorial responsibility: Ian A. Fleming, St. John's, Newfoundland and Labrador, Canada declines in North American Atlantic salmon populations. Mar Ecol Prog Ser 601:203-213

St John J, Russ GR, Gladstone W (1990) Accuracy and bias of visual estimates of numbers, size structure and biomass of a coral reef fish. Mar Ecol Prog Ser 64:253-262

Svenning MA, Lamberg A, Dempson B, Strand R, Hanssen $\varnothing K$, Fauchald P (2017) Incidence and timing of wild and escaped farmed Atlantic salmon (Salmo salar) in Norwegian rivers inferred from video surveillance monitoring. Ecol Freshwat Fish 26:360-370

Taranger GL, Karlsen Ø, Bannister RJ, Glover KA and others (2015) Risk assessment of the environmental impact of Norwegian Atlantic salmon farming. ICES J Mar Sci 72: 997-1021

* Thurow RF, Peterson JT, Guzevich JW (2006) Utility and validation of day and night snorkel counts for estimating bull trout abundance in first-to third-order streams. N Am J Fish Manage 26:217-232

Toft JD, Cordell JR, Simenstad CA, Stamatiou LA (2007) Fish distribution, abundance, and behavior along city shoreline types in Puget Sound. N Am J Fish Manage 27: $465-480$

Vollset KW, Skoglund H, Barlaup BT, Pulg U and others (2014) Can the river location within a fjord explain the density of Atlantic salmon and sea trout? Mar Biol Res 10: 268-278

*Walker AM, Beveridge MCM, Crozier W, Ó Maoiléidigh N, Milner N (2006) Monitoring the incidence of escaped farmed Atlantic salmon, Salmo salar L., in rivers and fisheries of the United Kingdom and Ireland: current progress and recommendations for future programmes. ICES J Mar Sci 63:1201-1210

Wilcove DS, Rothstein D, Dubow J, Phillips A, Losos E (1998) Quantifying threats to imperiled species in the United States. BioScience 48:607-615

Wringe BF, Jeffery NW, Stanley RRE, Hamilton LC and others (2018) Extensive hybridization following a large escape of domesticated Atlantic salmon in the Northwest Atlantic. Commun Biol 1:108

Submitted: April 26, 2019; Accepted: July 3, 2019 Proofs received from author(s): August 19, 2019 